\title{
Efficacy of ivermectin for control of the salmon louse Lepeophtheirus salmonis on Atlantic salmon
}

\author{
S. C. Johnson ${ }^{1,2}$, L. Margolis ${ }^{1}$ \\ ${ }^{1}$ Department of Fisheries and Oceans, Biological Sciences Branch, Pacific Biological Station, Nanaimo, British Columbia, \\ Canada V9R 5K6 \\ ${ }^{2}$ Department of Zoology, University of British Columbia, Vancouver, British Columbia, Canada V6T 2A9
}

\begin{abstract}
The efficacy of orally administered ivermectin against the common salmon louse Lepeophtheirus salmonis on Atlantic salmon Salmo salar was investigated under laboratory conditions. Both 3 and 6 doses of ivermectin at a targeted dose of $0.05 \mathrm{mg} \mathrm{kg}^{-1}$ fish administered in the feed every third day arrested the development and reduced the intensity of infection by $L$. salmonis. This is the first report of an efficacious treatment against the chalimus stages of sea lice. Serious head and dorsal body lesions, typical of $L$. salmonis feeding activity, which developed on the control fish were absent from the ivermectin-treated fish. lvermectin fed at these dosage regimes resulted in a darkenıng of the fish, but appeared not to reduce their feeding activity.
\end{abstract}

KEY WORDS: Ivermectin Lepeophtheirus salmonis Parasite control Parasite treatment - Salmon louse Salmo salar Sea lice

\section{INTRODUCTION}

The marine ectoparasitic copepod Lepeophtheirus salmonis is one of several species of sea lice that commonly infect, and can cause serious disease in, sea-farmed salmonids (Brandal \& Egidius 1979, Kabata 1979, 1988, Pike 1989, Wootten et al. 1982). This species has a direct life cycle consisting of 5 phases and 10 stages. These include 2 freeswimming naupliar stages, 1 free-swimming infectious copepodid stage, 4 attached chalimus stages, 2 preadult stages, and an adult stage (Johnson \& Albright 1991).

Currently, epizootics of Lepeophtheirus salmonis on farmed Atlantic salmon Salmo salar are treated in Europe by bath treatments with dichlorvos, the active ingredient in 'Nuvan 500EC' or 'Aquaguard' (Grave et al. 1991a, b, Jackson \& Costello 1992, Roth et al. 1993). These treatments are labour-intensive and highly stressful to the fish, and populations of $L$. salmonis are reported to be developing resistance to these chemicals (Jones et al. 1992). These problems, as well as concerns of environmental groups about the release of dichlorvos into the marine environment, have made the development of alternative treatment methods for sea lice a priority.

Orally administered ivermectin (22,23-Dihydroavermectin $B_{1}$ ) has been reported to be effective for the control of sea lice and other parasitic copepods on Atlantic salmon (Palmer et al. 1987, Smith \& Clarke 1988, O'Halloran et al. 1992, Smith et al. 1992, 1993). Currently, ivermectin administered orally at a dosage level of $0.05 \mathrm{mg} \mathrm{kg}^{-1}$ fish twice weekly is used as a treatment for sea lice in Ireland and possibly Scotland (Jackson \& Costello 1992, Roth et al. 1993). At this dose, ivermectin has been reported to be non-toxic and effective in controlling sea lice (Jackson \& Costello 1992, Smith et al. 1993). Johnson et al. (1993) reported on the toxicity and histopathological effects of ivermectin on salmon. They reported that ivermectin fed to Atlantic salmon at a targeted dose rate of $0.05 \mathrm{mg} \mathrm{kg}^{-1}$ every second day for $50 \mathrm{~d}$ resulted in $10 \%$ cumulative mortality over the $65 \mathrm{~d}$ of the study. After 6 doses of ivermectin, the treated fish showed a darkened colouration, reduced feeding activity, and some loss of equilibrium. 
No histopathological effects of ivermectin on the major organs were observed in their study.

The objective of the present study was to investigate the efficacy of orally administered ivermectin for the control of the salmon louse Lepeophtheirus salmonis on Atlantic salmon.

\section{MATERIALS AND METHODS}

Ovigerous Lepeophtheirus salmonis were collected from wild chinook salmon Oncorhynchus tshawytscha and sea-farmed Atlantic salmon Salmo salar from the Strait of Georgia, British Columbia, Canada. Eggs and developing larvae were cultured in a $45 \mathrm{l}$ tank supplied with flowing sand-filtered seawater (ca 4 l min $^{-1}$ ) at 10.8 to $12.1{ }^{\circ} \mathrm{C}$ and ambient salinity (29 to $31 \%$. Circulation within the tank was maintained by gentle aeration. Nitex screens $(100 \mu \mathrm{m}$ mesh) were attached to the drain to prevent copepod loss.

Naive Atlantic salmon, 16.1 to $21.7 \mathrm{~cm}$ fork length and 47.0 to $149.3 \mathrm{~g}$ wet weight, were transferred to a 500 I tank and infected with newly moulted copepodid larvae under conditions of darkness, low water flow, and aeration. Nitex screens (180 $\mu \mathrm{m}$ mesh) were attached to the tank drains to prevent copepodid loss. Fish were maintained in flowing sand-filtered seawater at 11.0 to $13.3^{\circ} \mathrm{C}$ and ambient salinity (29 to $31 \%$ )

Ivermectin used in our experiment was in the form of a veterinary preparation of $1 \% \mathrm{w} / \mathrm{v}$ oral drench (Eqvalan; Merck Frosst Canada). Commercial salmon pellets (White Crest) were allowed to dry for $24 \mathrm{~h}$ at room temperature and sprayed with a solution of Eqvalan diluted with distilled deionized water. Diets were stored frozen in sealed containers until used. The level of ivermectin in the treated feed was confirmed by the Health of Animals Laboratory, Agriculture Canada, Saskatoon, following the methods given in Doherty et al. (1990). The diets of Trials 1 and 2 contained 62.1 and $61.0 \%$, respectively, of their targeted concentrations.

A $1.0 \%$ body weight food ration containing ivermectin at a targeted dose of $0.05 \mathrm{mg}$ ivermectin $\mathrm{kg}^{-1}$ fish was fed every third day. Fish received either 3 or 6 doses of ivermectin. Untreated diet was fed on the other days at a level of $1.0 \%$ of body weight per day.

In Trial 1, 105 Atlantic salmon that had been infected in the laboratory were divided into 3 equal groups. Each group was assigned to either a 3-dose, a 6-dose, or a control group. Five fish from each treatment and control group were sampled prior to treatment and the intensity of Lepeophtheirus salmonis determined. Fish in the 3-dose and control groups were sampled at 14 (10 treated fish and 10 control fish) and 21 (11 treated fish and 10 control fish) days post-treatment. Thirteen fish in the 6-dose group were sampled at $21 \mathrm{~d}$ posttreatment. Twenty fish died during the trial and the remaining 6 fish were not sampled.

In Trial 2, 106 Atlantic salmon that had been infected in the laboratory were divided into 2 equal groups and assigned to either a 6 -dose or a control group. Prior to treatment, 5 fish from each group were sampled and the intensity of Lepeophtheirus salmonis determined. Ten fish from each group were sampled at 21 and $28 \mathrm{~d}$ post-treatment. Twenty-one fish died during the trial and the remaining fish were not sampled.

Fish were killed by a blow to the head, and their fork lengths and wet weights determined. The body surfaces, including the gills, were examined for copepods and the distribution of the copepods on the fish was recorded. The number of copepods present was corrected to a standard wet body weight to compensate for differences in size among hosts.

Intensity data were $\log (x+1)$ transformed to normalize their distribution, and differences in copepod intensity (number of parasites per infected host) investigated by analysis of variance (ANOVA) procedures or t-tests. Comparisons of copepod intensity for the control and treatment groups over time as well as between different groups at each sampling period were made using either t-tests or Scheffé's tests. Stage distribution data were compared between groups using a chisquare statistic (Zar 1984)

\section{RESULTS}

Prior to treatment there was no significant difference $(1$-way ANOVA and $t$-test; $p<0.05)$ in the intensity of Lepeophtheirus salmonis between treatment and control groups in either trial (Fig. 1).

In Trial 1, the intensity of infection for both the control and 3-dose group was significantly different over time (1-way ANOVA; $\mathrm{p}<0.001$ ). The results of multiple range tests of copepod intensity showed significant differences among all 3 samples of the control fish (Scheffé's test; $p<0.05$ ). In the 3 -dose group there were significantly more copepods present prior to treatment than at either 14 or $21 \mathrm{~d}$ and there was no significant difference in intensity between $14 \mathrm{~d}$ and $21 \mathrm{~d}$ (Scheffé's test; $\mathrm{p}<0.05$ ). There were significantly fewer parasites present at Day 21 than prior to treatment in the 6 -dose treatment $(t$-test; $p<0.01$ ). There was no significant difference in the intensity of copepods between the control and 3-dose group at $14 \mathrm{~d}$ ( $t$-test; $p>0.05$ ), or between any of the 3 groups at 21 d. (1-way ANOVA; $p>0.05)$

In Trial 2, the intensity of infection for both the control and 6-dose groups was significantly different over 


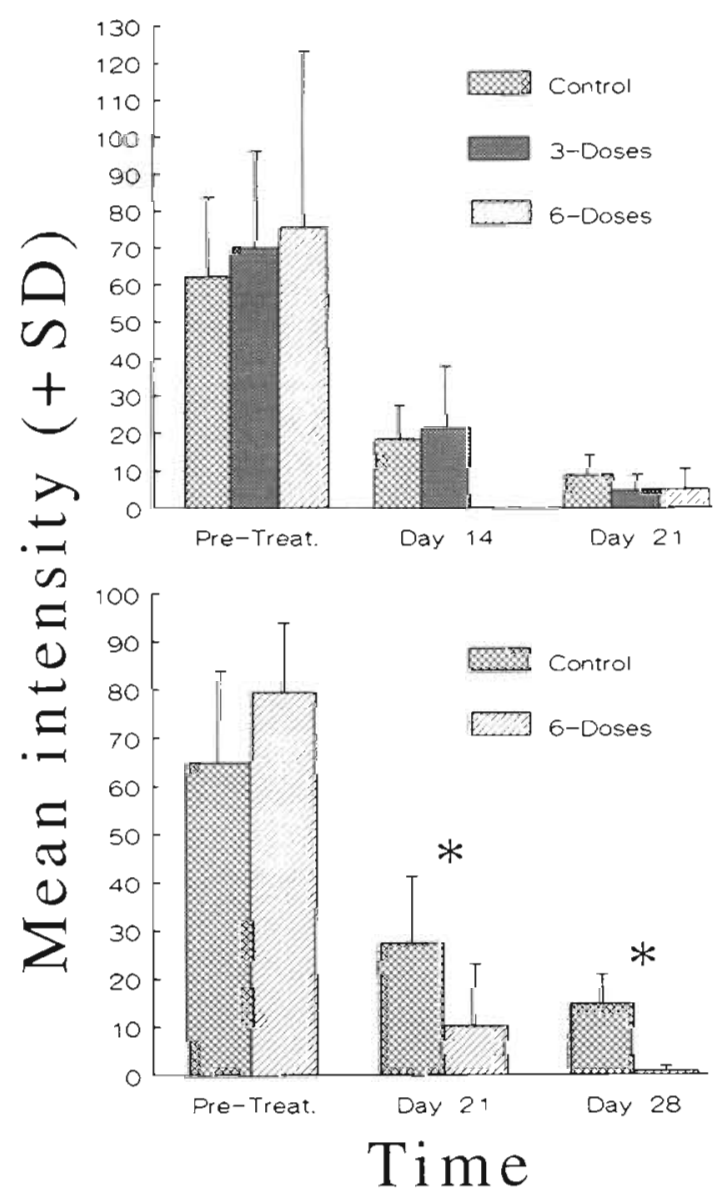

Fig. 1. Mean (+SD) intensity of Lepeophtheirus salmonis on control and ivermectin-treated Atlantic salmon in Trial 1 (upper) and Trial 2 (lower). Fish were fed either 3 or 6 doses of ivermectin at a targeted level of $0.05 \mathrm{mg} \mathrm{kg}^{-1}$ every third day. Fish were maintained at 11.0 to $13.3^{\circ} \mathrm{C}$ and ambient salinity (29 to $31 \%$. An $\cdot$ above error bars indicates significant differences in intensity between groups ( $t$-test; $p<0.05)$

time (1-way ANOVA; $p<0.001)$. The results of multiple range tests of copepod intensity showed significant differences among all 3 samples of both the control and 6-dose groups (Scheffé's test: $p<0.05$ ). There were significantly fewer copepods present on the treated group than on the control group at Days $21 \& 28$ ( $t$-test; $\mathrm{p}<0.05)$.

Lepeophtheirus salmonis developed faster on the control fish than on the treated groups (Fig. 2). There were significant differences in the stage composition of copepods between the control and 3-dose groups at $14 \mathrm{~d}$ (Pearson's chi-square; $\mathrm{p}<0.001$ ), between the control and both the 3 - and 6-dose groups at $21 \mathrm{~d}$ in Trial 1 (Pearson's chi-square $; p<0.001$ ), and between the control and 6-dose group at Day 21 in Trial 2 (Pearson's chi-square; $p<0.001$ ). Too few copepods
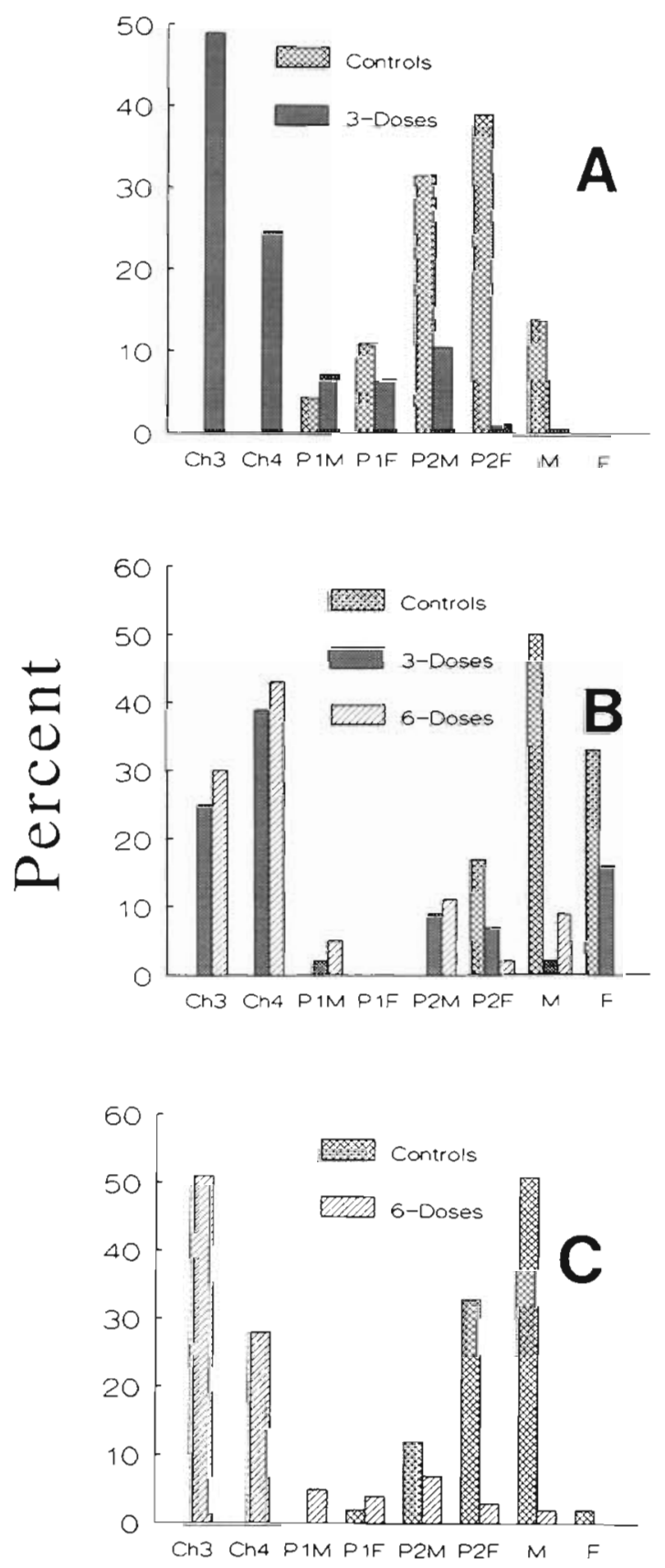

Developmental Stage

Fig. 2. Lepeophtheirus salmonis stage distributions on control and ivermectin-treated Atlantic salmon Salmo salar in 2 trials. Fish were fed either 3 or 6 doses of ivermectin at a targeted level of $0.05 \mathrm{mg} \mathrm{kg}^{-1}$ every third day. (A) Trial 1 samples collected 1 wk after the third dose (Day 14). (B) Trial 1 samples collected 1 wk after the sixth dose (Day 21). (C) Trial 2 samples collected 1 wk after the sixth dose (Day 21). Fish were maintained at 11.0 to $13.3^{\circ} \mathrm{C}$ and ambient salinity (29 to $31 \%$. Ch3 = third chalimus; $\mathrm{Ch} 4=$ fourth chalimus; $\mathrm{P} 1 \mathrm{M}=$ first preadult male; $\mathrm{P} 1 \mathrm{~F}=$ first preadult female; $\mathrm{P} 2 \mathrm{M}=$ second preadult male; $\mathrm{P} 2 \mathrm{~F}=$ second preadult female; $\mathrm{M}=$ adult male; $F=$ adult female 
were recovered at Day 28 from the 6-dose group to enable a statistical comparison of their developmental stage composition with that on the control fish. Of the 9 copepods collected from the 6 -dose group, $33 \%$ were fourth chalimus larvae, $11 \%$ were preadult males, $44 \%$ were males, and $11 \%$ were females. Of the 179 copepods collected from the control group, $5 \%$ were first preadult females, $1 \%$ were second preadult males, $11 \%$ were second preadult females, $49 \%$ were adult males, and $33 \%$ were adult females.

In Trial 1, there was no significant difference in the developmental stage composition of copepods between the 3 - and 6-dose groups at $21 \mathrm{~d}$ (Pearson's chisquare; $p<0.231$ ), and a significant difference in the 3 -dose group between 14 and 21 d (Pearson's chisquare; $p<0.001$ ).

In Trial 1, cumulative mortalities over the $21 \mathrm{~d}$ of the experiment were $27 \%$ in the control fish, $13 \%$ in the $3-$ dose group, and $20 \%$ in the 6 -dose group. In Trial 2 , cumulative mortalities over the $28 \mathrm{~d}$ of the experiment were $25 \%$ in the controls and $12 \%$ in the 6 -dose group. In Trial 1 , the fish in the control group had lesions caused by the feeding activities of Lepeophtheirus salmonis developing behind their dorsal and in some cases their adipose fins at $21 \mathrm{~d}$. In Trial 2, welldeveloped lesions which had breached the dermis were present on the heads and dorsal surface of the majority of the control fish. No lesions were evident on the ivermectin-treated fish in either trial. In both trials and at both dose regimes the treated fish were markedly darker than the control fish. When compared to the controls no reduction in the feeding activity of the ivermectin-treated fish was noted in either trial.

\section{DISCUSSION}

In our study ivermectin administered orally to Atlantic salmon at a targeted dosage of $0.05 \mathrm{mg} \mathrm{kg}^{-1}$ every third day for either 3 or 6 doses arrested the development and reduced the intensity of infection by Lepeophtheirus salmonis. Assays of ivermectin levels in the medicated feeds conducted approximately 1 mo after the termination of these experiments recovered approximately $60 \%$ of the targeted levels. Possible explanations for these discrepancies include uneven spaying of the feed, or loss of ivermectin during frozen storage. Because we do not know at which stage (e.g. during diet preparation or storage) this loss occurred it is possible that the fish received a lower dose than targeted. Further studies should be conducted to determine if lower doses of ivermectin are efficacious against $L$. salmonis and other species of sea lice. Other authors have reported that a single $0.2 \mathrm{mg} \mathrm{kg}^{-1}$ oral dose was effective against both the juvenile (chalimus and preadult) and adult stages of both $L$. salmonis and Caligus elongatus, and, although reinfection with copepodids did occur, survival to the chalimus stages was impaired (Palmer et al. 1987). Smith et al. (1993) reported median percentage reductions in sea lice of: 81 and $97 \%$ following treatment at $0.2 \mathrm{mg} \mathrm{kg}^{-1}$ every $2 \mathrm{wk}_{\mathrm{i}} 91 \%$ following treatment at $0.075 \mathrm{mg} \mathrm{kg} \mathrm{kg}^{-1}$ twice a week 76 and $92 \%$ following treatment at $0.1 \mathrm{mg} \mathrm{kg}^{-1}$ once a week; and 89 and $93 \%$ following $0.05 \mathrm{mg} \mathrm{kg}^{-1}$ twice a week. The results of Smith et al. (1993) and our findings suggest that a dose of $0.05 \mathrm{mg}$ $\mathrm{kg}^{-1}$ fed twice per week is effective against all of the developmental stages of sea lice found on the fish. Spencer (1992) reviewed unpublished research on the treatment of Atlantic salmon smolts with $0.02 \mathrm{mg} \mathrm{kg}^{-1}$ once a week for a period of 2 to 3 mo. At this level, ivermectin was reported to take about $3 \mathrm{wk}$ to act and to be effective in preventing reinfection for about 4 wk after termination of treatment. O'Halloran et al. (1992) reported that a single dose of ivermectin fed at $0.2 \mathrm{mg} \mathrm{kg}^{-1}$ fish resulted in a marked decrease (98 to $99 \%$ ) in the intensity of the parasitic copepod Ergasilus labracis on Atlantic salmon, but also caused some increase in the mortality rate of the fish. Feeding of a $0.05 \mathrm{mg} \mathrm{kg}^{-1}$ dose twice weekly gave a similar reduction in the intensity of E. labracis, with no increase in the mortality rate of the fish. In our studies, cumulative mortalities ranged between 12 and $20 \%$ for the treated fish. The majority of the fish which died had not been feeding and several showed signs of vibriosis.

Ivermectin is the first compound demonstrated to be efficacious against the chalimus stages of sea lice. Efficacy against the chalimus stages increases the duration between treatments required to maintain sea lice intensities at acceptable low levels. Ivermectin is also reported to protect fish from re-infection after termination of the treatment, although the duration of such protection remains to be determined (Palmer et al. 1987, Jackson \& Costello 1992, Spencer 1992). If the duration of protection is sufficiently long, treatment of hatchery-reared fish with ivermectin prior to their release to the sea may protect them against losses due to sea lice infection during their early sea life. Sea lice infection of wild stocks of sea-run brown trout Salmo trutta has been reported to cause serious disease in areas of extensive sea farming of Atlantic salmon in Ireland (Tully et al. 1993).

Major drawbacks for the use of ivermectin include its toxicity to salmon, its long tissue withdrawal time and its unknown effects on non-target organisms and the environment. Cumulative mortalities of $80 \%$ and greater were reported for Atlantic salmon fed 3 doses of ivermectin at a targeted concentration of $0.20 \mathrm{mg}$ $\mathrm{kg}^{-1}$ fish, or 1 dose of ivermectin at targeted concentrations of 0.50 or $1.0 \mathrm{mg} \mathrm{kg}^{-1}$ fish (Johnson et al. 
1993). Jackson \& Costello (1992) report a tissue withdrawal time of 700 degree days and note that this limits its use to treatment of infections in smolts. To date there are no data on the ecological effects of ivermectin in the marine environment. Before ivermectin can be considered for field use, further studies of tissue residue levels and withdrawal times, as well as its effects on non-target organisms and persistence within the sediments beneath the net pens, need to be undertaken.

Acknowledgements. We thank Dr T Evelyn for critically reviewing this manuscript, and $\mathrm{Mr}$ C. Salisbury of the Health of Animals Laboratory, Agriculture Canada, Saskatoon, for the analysis of ivermectin in the treated feeds. This research was funded by the Department of Fisheries and Ocean's Biological Sciences Branch, Pacific Region, and was conducted at the Pacific Biological Station. S.C.J. was supported by a Natural Sciences and Engineering Research Council of Canada Postdoctoral Fellowship.

\section{LITERATURE CITED}

Brandal, P. O., Egidius, E. (1979). Treatment of salmon lice (Lepeophtheirus salmonis Kroyer, 1838) with Neguvon ${ }^{\mathrm{R}}$ description of method and equipment. Aquaculture, 18: $183-188$

Doherty, S. J., Fox, A., Fink, D. W. (1990). Determination of ivermectin in medicated swine feeds at the 2 ppm concentration level. J. Ass. off. analyt. Chem. 73: 931-934

Grave, K., Engelstad, M., Soli, N. E. (1991a). Utilization of dichlorvos and trichlorfon in salmonid farming in Norway during 1981-1988. Acta vet. scand. 32: 1-7

Grave, K., Engelstad, M., Soli, N. E., Toverud, E.-L. (1991b) Clinical use of dichlorvos (Nuvan) and trichlorfon (Neguvon) in the treatment of the salmon louse, Lepeophtheirus salmonis. Compliance with the recommended treatment procedures. Acta. vet. scand. 32: 9-14

Jackson, D., Costello, M. J. (1992). Dichlorvos and alternative sealice treatments. In: De Pauw, N., Joyce, J. (eds.) Aquaculture and the environment. 1991. Spec. Publ. Eur. Aquacult. Soc. 16: 215-221

Johnson, S. C., Albright, L. J. (1991). The developmental stages of Lepeophtheirus salmonis (Krøyer, 1837) (Copepoda: Caligidae). Can. J. Zool. 69: 929-950

Johnson, S. C., Kent, M. L., Whitaker, D. J., Margolis, L. (1993). Toxicity and pathological effects of orally administered ivermectin in Atlantic, chinook, and coho salmon and steelhead trout. Dis. aquat. Org. 17: 107-112

Jones, M. W., Sommerville, C., Wootten, R. (1992). Reduced sensitivity of the salmon louse, Lepeophtheirus salmonis, to the organophosphate dichlorvos. J Fish Dis. 15: $197-202$

Kabata, Z. (1979). Parasitic Copepoda of British fishes. The Ray Society, London

Kabata, Z. (1988). Copepoda and Branchiura. In: Margolis, L., Kabata, Z. (eds.) Guide to the parasites of fishes of Canada. Part II. Crustacea. Can. Spec. Publ. Fish. Aquat. Sci. 101. 3-127

O'Halloran, J. Carpenter, D. O. Hogans, W E Jansen, M. (1992). Ergasilus labracis on Atlantic salmon. Can. vet. J. 33: 75

Palmer, R., Rodger, H., Drinan, E., Dwyer, C., Smith, P. R. (1987). Preliminary trials on the efficacy of ivermectin against parasitic copepods of Atlantic salmon. Bull. Eur. Ass. Fish Pathol. 7: 47-54

Pike, A. W (1989). Sea lice - major pathogens of farmed Atlantic salmon. Parasitol. Today 5: 291-297

Roth, M., Richards, R. H., Sommerville, C. (1993). Current practices in the chemotherapeutic control of sea lice infestations in aquaculture. J. Fish Dis. 16: 1-26

Smith, P. R., Clarke, S. D. (1988). An orally administered alternative to the organophosphate 'Nuvan' for the control of sea lice in cage farmed Atlantic salmon. Aquaculture International Congress Abstracts, Vancouver, BC, Canada, Sept. 6-9, 1988, p. 80

Smith, P., Moloney, M., McElligott, A., Clarke, S., O'Brien, F. (1992). Studies of the efficacy of orally administered ivermectin as a method for the control of sea lice infestations of farmed atlantic salmon. First European Crustacean Conference Abstracts, Paris, France, Aug. 31-Sept. 5, 1992, p. 149

Smith, P. R., Moloney, M., McElligott, A., Clarke, S., Palmer. R., O'Kelly, J., O'Brien, F. (1993). The efficiency of oral ivermectin in the control of sea lice infestation of farmed Atlantic salmon. In: Boxshall, G. A., DeFaye, D. (eds.) Pathogens of wild and farmed fish: sea lice. Ellis Horwood, Chichester, p. 296-307

Spencer, R. J. (1992). The future for sea lice control in cultured salmonids: a review. Technical Report to the Marine Working Group of Scottish Wildlife and Countryside Link. (Available from The Secretary, PO Box 64, Perth PH2 OTF, Scotland)

Tully, O., Poole, W. R., Whelan, K. F. (1993). Infestation parameters for Lepeophtheirus salmonis (Krøyer) (Copepoda: Caligidae) parasitic on sea trout (Salmo trutta L.) off the west coast of Ireland during 1990 and 1991. Aquacult. Fish. Mgmt 24: 545-555

Wootten, R., Smith, J. W., Needham, E. A. (1982). Aspects of the biology of the parasitic copepods Lepeophtheirus salmonis and Caligus elongatus on farmed salmonids, and their treatment. Proc. R. Soc. Edinb. (Sect. B) 81: 185-197

Zar, J H. (1984). Biostatistical analysis. Prentice Hall, Englewood Cliffs

Manuscript first received: March 22, 1993

Revised version accepted: June 6, 1993 